NBER WORKING PAPER SERIES

\title{
ENVIRONMENTAL TAX INTERACTIONS WHEN \\ POLLUTION AFFECTS HEALTH OR PRODUCTIVITY
}

Roberton C. Williams III

Working Paper 8049

http://www.nber.org/papers/w8049

\author{
NATIONAL BUREAU OF ECONOMIC RESEARCH \\ 1050 Massachusetts Avenue \\ Cambridge, MA 02138 \\ December 2000
}

The author would like to thank Larry Goulder, Dallas Burtraw, Ruud de Mooij, Ian Parry, Lans Bovenberg, and seminar participants at Stanford University and Resources For the Future for their suggestions on this topic. The views expressed in this paper are those of the author and not necessarily those of the National Bureau of Economic Research.

(C) 2000 by Roberton C. Williams III. All rights reserved. Short sections of text, not to exceed two paragraphs, may be quoted without explicit permission provided that full credit, including $(\mathrm{C}$ notice, is given to the source. 
Environmental Tax Interactions When Pollution Affects Health or Productivity

Roberton C. Williams III

NBER Working Paper No. 8049

December 2000

JEL No. L51, H21, I18, H23

\begin{abstract}
Numerous recent studies have indicated that interactions with a tax-distorted labor market increase the cost of pollution regulation. However, these studies have made restrictive assumptions regarding individual preferences and have ignored key links between pollution, human health, and labor productivity. Together, these assumptions imply that the benefits of regulation do not affect labor supply.

This paper develops an analytically tractable general equilibrium model that allows regulation to provide benefits through several different channels, including improved health or productivity. The model shows that when the benefits of reduced pollution come in the form of improved health or productivity, the benefits do affect labor supply, and therefore create a benefit-side tax-interaction effect in addition to the familiar cost-side interaction. This effect can magnify or diminish the benefits of reduced pollution. When reduced pollution boosts labor productivity, the effect substantially magnifies such benefits. When pollution affects consumer health, the effect will tend to be opposite, diminishing the benefits of reduced pollution.

This result is of far more than just theoretical interest; the benefit-side interaction is of the same magnitude as the cost-side interaction, and thus can fundamentally affect the optimal level of regulation. The paper considers only environmental regulation, but the concepts developed here apply equally to other policies affecting productivity or health, such as research subsidies or occupational safety regulations.
\end{abstract}

\author{
Roberton C. Williams \\ Department of Economics \\ University of Texas \\ Austin, TX 78712 \\ and NBER \\ rwilliam@eco.utexas.edu
}




\section{Introduction}

One of the most important tasks that economists face in environmental policymaking is the evaluation of the costs and benefits of existing and proposed regulations. For example, the EPA recently conducted extensive prospective and retrospective analyses of the costs of the Clean Air Act (EPA, 1997 and 1999). Those analyses, and others like them, will play an important role in determining future policies.

An extensive recent literature has called into question the results of conventional analyses of the costs of environmental regulation. This literature has focused on two generalequilibrium effects that appear in an economy with pre-existing distortionary taxes. ${ }^{1}$ The first, the revenue-recycling effect, appears when a pollution tax or similar instrument generates revenue for the government, thus permitting a reduction in distortionary tax rates and a corresponding gain in efficiency. This gain is offset by a loss from the tax-interaction effect, which arises because the pollution tax drives up the price of consumption goods, lowering the real wage and discouraging labor supply. This exacerbates the tax distortion in the labor market, creating an efficiency loss. As a result of these interactions, the economy-wide costs of regulation may differ substantially from the sum of firms' abatement costs.

As this paper will show, however, general-equilibrium interactions can have an equally large effect on the benefits of environmental regulation. This effect has largely been ignored by the prior literature, which has implicitly assumed that improved environmental quality does not influence individuals' labor supply decisions, and therefore that the benefits of reduced pollution are unchanged from the first-best case. That assumption may be valid in certain cases, such as the protection of an endangered species with substantial existence value, which could be represented as a separable term in consumer utility. It is a much less reasonable assumption, however, for the wide range of cases in which pollution affects productivity or health.

Such cases are of substantial interest for environmental policy. For example, a significant proportion of the benefits of avoiding global warming appear in the form of

\footnotetext{
${ }^{1}$ Among the many papers on this topic are Bovenberg and de Mooij (1994), Bovenberg and van der Ploeg (1994), Parry (1995), Goulder (1995), Goulder, Parry, and Burtraw (1997), and Fullerton and Metcalf (2000).
} 
avoided losses to agricultural productivity, while much of the damages from airborne pollutants such as sulfur dioxide and particulate emissions appear as damages to human health. In these cases, the benefits of pollution regulation also affect labor supply decisions, producing an additional tax-interaction effect ${ }^{2}$ from the benefits of regulation. This benefitside tax-interaction effect varies greatly depending on the effects of the pollutant in question, and can either magnify or diminish the benefits of pollution regulation.

This paper presents a model of environmental regulation that allows pollution to have a wide range of different effects, including not only direct effects on utility, but also productivity effects in different industries and a range of health effects.

The paper demonstrates that when reduced pollution leads to increased labor productivity, this will encourage labor supply, and thus tax interactions will magnify the benefits of regulation. In contrast, if a cleaner environment boosts the productivity of a fixed factor, then tax interactions will reduce the benefit of regulation.

When the benefits of reduced pollution appear in the form of reduced medical expenses, this creates an income effect that discourages labor supply, and thus such benefits are diminished by the benefit-side tax-interaction effect. When pollution causes increased time lost to illness (but does not affect medical expenses) the sign of the benefit-side taxinteraction effect is ambiguous, and depends on the labor tax rate and labor supply elasticity.

Though the model explicitly considers environmental regulation, its results and the concept of the benefit-side tax-interaction effect apply equally to other types of regulation affecting health or productivity.

The next section of the paper presents an analytically tractable general-equilibrium model that allows for a broad range of effects of pollution and derives an expression for the welfare effects of regulation. The following sections evaluate this expression for pollutants that affect only utility, pollutants that affect productivity, and pollutants that affect health.

\footnotetext{
${ }^{2}$ The prior literature has referred to a single tax-interaction effect. This paper extends that concept to a general class of tax-interaction effects. These effects are general equilibrium welfare changes resulting from changes in the quantity demanded of a taxed good caused by forces outside the market for that good. The previously identified tax-interaction effect is a change in the demand for leisure caused when the cost of regulation drives up the price of consumer goods. The benefit-side tax-interaction effect introduced in this paper is a change in the demand for leisure resulting from improved environmental quality.
} 
The final section discusses potential extensions to this model, suggests avenues for future work and draws conclusions for policy decisions.

\section{The Model}

This section presents a simple general-equilibrium model that incorporates a household labor-leisure decision along with a pollution externality. Thus, the model incorporates production of two goods, one of which has an associated pollution externality, and includes a government sector and distortionary income tax.

This model takes a similar approach to the analytical model used by Parry, Williams, and Goulder (1999) to examine the effects of carbon emissions regulation in a tax-distorted economy. This model is distinct, however, in that environmental quality no longer appears only as a separable term in the utility function, but also may affect production efficiency and the health of the representative agent. Furthermore, this model generalizes the production function, allowing for the possibility of profits in production, which prove to play an important role in determining the effects of pollution regulation in the presence of distortionary taxation.

\section{A. Assumptions}

A representative agent model is assumed, where households divide their time endowment $(T)$ between leisure $(l)$ and labor $(L)$, which is used to produce the two consumption goods, $X$ and $Y$. Households divide their income between consumption of $X$ and $Y$ in order to maximize the utility function

$$
U(V(l, X, Y), Q)
$$

which is continuous and quasi-concave, and where $Q$ is environmental quality.

Good $X$ causes a negative externality, either in consumption or in production (since consumption equals production in this model, the two are equivalent) while good $Y$ involves no such externality. Environmental quality is simply equal to an exogenous baseline level minus emissions, with units normalized such that the production and consumption of one unit of $\mathrm{X}$ results in one unit of emissions: 


$$
Q=\bar{Q}-X
$$

This model allows environmental quality to have several different possible effects. The simplest case follows previous work in assuming that the externality enters as a separable term in the utility function. Alternatively, the externality could affect production of one or both of the consumption goods. Thus, production of the two consumption goods will follow

$$
X=F_{X}\left(L_{X}, Q\right)
$$

and

$$
Y=F_{Y}\left(L_{Y}, Q\right)
$$

where $L_{X}$ and $L_{Y}$ are the labor used in production of goods $X$ and $Y$, respectively.

Finally, the externality could affect the health of the population, either causing the representative agent to spend time sick (reducing the time available for labor or leisure) or by forcing expenditure on medical care ${ }^{3}$ (which is assumed to be produced directly from labor, with one unit of labor producing one unit of medical care). This implies the following household time constraint

$$
T=L+l+S(Q)=L_{X}+L_{Y}+L_{M}+l+S(Q)
$$

where $S(Q)$ represents time spent sick, which is decreasing in $Q$, and $L_{M}$ is the labor used to produce medical care.

To control this externality, the government levies a corrective tax of $\tau_{x}$ per unit of the dirty good, $X$. Previous papers ${ }^{4}$ have shown that there is a substantial cost advantage to using an environmental tax in preference to a quota or system of grandfathered tradable permits in the presence of distortionary labor taxation, because of the efficiency gain from recycling the pollution tax revenues. Because this paper is not concerned with the distinction between taxes and quotas, it models only the use of a corrective tax. Both industries are assumed to price

\footnotetext{
${ }^{3}$ Section II.E relaxes the assumption that pollution forces households to purchase medical care, allowing households to choose the level of medical care they consume.

${ }^{4}$ See, for example, Goulder, Parry, and Burtraw (1997), Parry, Williams, and Goulder (1999), Goulder et al (1999), and Fullerton and Metcalf (2000).
} 
output at marginal cost and pay labor its marginal product, and the gross wage is normalized to 1 . The price of good $X$ (including the tax) is then given by:

$$
p_{X}=\frac{1}{\frac{\partial F_{X}}{\partial L_{X}}}+\tau_{X}
$$

Since there is no tax on good $Y$, its price is given by:

$$
p_{Y}=\frac{1}{\frac{\partial F_{Y}}{\partial L_{Y}}}
$$

If either production function is not homogenous of degree one in labor input, there will be profits in production of that good, which implicitly represent rents to some fixed factor in production. Total profits, $(\pi)$, which are assumed to accrue to households, follow

$$
\pi=\left(p_{X}-\tau_{X}\right) X+p_{Y} Y-L_{X}-L_{Y}
$$

Finally, the government levies a tax on all income at the rate $\tau_{\mathrm{L}}$ in order to finance government spending $(G)$, which is assumed to consist entirely of transfers to households, and is exogenously fixed. Thus, the household budget constraint is:

$$
\left(1-\tau_{L}\right)(L+\pi+G)=p_{X} X+p_{Y} Y+M(Q)
$$

where $M(Q)$ represents medical care required, which is decreasing in $Q$ and is produced following $M=L_{M}$. The government's budget constraint is

$$
G=\tau_{L}(L+\pi+G)+\tau_{X} X
$$

Households maximize utility (1) subject to their time constraint (5) and budget constraint (9), taking government transfers, prices, the labor tax rate, and the environmental tax rate as given. This yields the first order conditions:

$$
U_{X}=p_{X} \lambda ; U_{Y}=p_{Y} \lambda ; U_{l}=\left(1-\tau_{L}\right) \lambda
$$

where $\lambda$ represents the marginal utility of income.

These first-order conditions, together with the other equations given thus far, implicitly define the Marshallian demand functions:

$$
X\left(p_{X}, p_{Y}, \tau_{L}, \pi, Q\right) ; Y\left(p_{X}, p_{Y}, \tau_{L}, \pi, Q\right) ; l\left(p_{X}, p_{Y}, \tau_{L}, \pi, Q\right)
$$


Note that while $G$ would ordinarily appear as an argument in these demand functions, because $G$ is fixed, it has been omitted.

\section{Effects of Taxing the Polluting Good}

Taking a derivative of utility with respect to the corrective tax $\left(\tau_{X}\right)$ while allowing $l, X$, and $Y$ to vary, substituting in the consumer first-order conditions, and dividing through by $\lambda$

yield

$$
\frac{1}{\lambda} \frac{d U}{d \tau_{X}}=p_{X} \frac{d X}{d \tau_{X}}+p_{Y} \frac{d Y}{d \tau_{X}}+\left(1-\tau_{L}\right) \frac{d l}{d \tau_{X}}-\frac{1}{\lambda} \frac{\partial U}{\partial Q} \frac{d X}{d \tau_{X}}
$$

Taking a derivative of the production equation for $\operatorname{good} X(3)$ with respect to $\tau_{X}$,

allowing $X$ and $L_{X}$ to vary, substituting in the equation for the price of $X(6)$ and solving for $\frac{d L_{X}}{d \tau_{X}}$ give

$$
\frac{d L_{X}}{d \tau_{X}}=\left(p_{X}-\tau_{X}\right)\left(\frac{d X}{d \tau_{X}}-\frac{\partial F_{X}}{\partial Q} \frac{d Q}{d \tau_{X}}\right)
$$

and a similar approach for good $Y$ yields

$$
\frac{d L_{Y}}{d \tau_{X}}=p_{Y}\left(\frac{d Y}{d \tau_{X}}-\frac{\partial F_{Y}}{\partial Q} \frac{d Q}{d \tau_{X}}\right)
$$

Taking a derivative of the household time constraint (5) with respect to $\tau_{X}$ while

allowing $l, L_{X}, L_{y}, X$, and $Y$ to vary gives

$$
\frac{d L_{X}}{d \tau_{X}}+\frac{d L_{Y}}{d \tau_{X}}+\frac{d l}{d \tau_{X}}-\left(\frac{\partial M}{\partial Q}+\frac{\partial S}{\partial Q}\right) \frac{d X}{d \tau_{X}}=0
$$

Substituting (14) and (15) into (16), subtracting from (13), and collecting terms yield

$$
\frac{1}{\lambda} \frac{d U}{d \tau_{X}}=\left(\tau_{X}-\tau_{P}\right) \frac{d X}{d \tau_{X}}-\tau_{L} \frac{d l}{d \tau_{X}}
$$

where $\tau_{P}$ is the Pigouvian tax level, equal to the marginal damage from emissions, including the effects on production, utility, and health, given by 


$$
\tau_{P}=\frac{\partial F_{X}}{\partial Q}\left(p_{X}-\tau_{X}\right)+\frac{\partial F_{Y}}{\partial Q} p_{Y}+\frac{1}{\lambda} \frac{\partial U}{\partial Q}-\frac{\partial M}{\partial Q}-\frac{\partial S}{\partial Q}
$$

Revenue raised by the tax on good $X$ allows an offsetting cut in the labor tax rate.

Taking a total derivative of the government budget constraint while holding $G$ constant, substituting in $\frac{d l}{d \tau_{X}}=\frac{\partial l}{\partial p_{X}} \frac{d p_{X}}{d \tau_{X}}+\frac{\partial l}{\partial p_{Y}} \frac{d p_{Y}}{d \tau_{X}}+\frac{\partial l}{\partial \tau_{L}} \frac{d \tau_{L}}{d \tau_{X}}+\frac{\partial l}{\partial \pi} \frac{d \pi}{d \tau_{X}}+\frac{\partial l}{\partial Q} \frac{d Q}{d \tau_{X}}$ and rearranging give an equation for the change in the labor tax rate:

$$
\frac{d \tau_{L}}{d \tau_{X}}=-\frac{X+\tau_{X} \frac{d X}{d \tau_{X}}-\tau_{L}\left(\frac{\partial l}{\partial p_{X}} \frac{d p_{X}}{d \tau_{X}}+\frac{\partial l}{\partial p_{Y}} \frac{d p_{Y}}{d \tau_{X}}\right)+\tau_{L}\left(1-\frac{\partial l}{\partial \pi}\right) \frac{d \pi}{d \tau_{X}}-\tau_{L}\left(\frac{\partial S}{\partial Q}+\frac{\partial l}{\partial Q}\right) \frac{d Q}{d \tau_{X}}}{(L+\pi+G)-\tau_{L} \frac{\partial l}{\partial \tau_{L}}}
$$

The ratio of the numerator to the denominator is the ratio of the marginal revenue from the tax on good $\mathrm{X}$ to the marginal revenue from the labor tax.

Define

$$
Z=\frac{\tau_{L} \frac{\partial l}{\partial \tau_{L}}}{(L+\pi+G)-\tau_{L} \frac{\partial l}{\partial \tau_{L}}}
$$

This is the efficiency cost of raising an additional dollar of labor tax revenue when revenue is not returned to households, or the marginal cost of public funds (MCPF) minus one. The numerator is therefore the marginal deadweight loss in the labor market, while the denominator is the marginal revenue from a change in the tax rate. ${ }^{5}$

$Z$ applies in the case in which revenue is not returned to households, because it does not include an income effect from increased transfers to households. The corresponding term that does include this income effect is the partial equilibrium marginal excess burden (MEB) of the labor tax, given by:

$$
Z^{\prime}=\frac{\tau_{L} \frac{\partial l^{C}}{\partial \tau_{L}}}{(L+\pi+G)-\tau_{L} \frac{\partial l}{\partial \tau_{L}}}
$$

\footnotetext{
${ }^{5}$ This is a "non-environmental" definition of the MCPF; it omits the effects of changes in environmental quality and environmental tax revenue that would result from a change in the labor tax.
} 
where the superscript "C" denotes a compensated derivative.

Substituting $\frac{d l}{d \tau_{X}}=\frac{\partial l}{\partial p_{X}} \frac{d p_{X}}{d \tau_{X}}+\frac{\partial l}{\partial p_{Y}} \frac{d p_{Y}}{d \tau_{X}}+\frac{\partial l}{\partial \tau_{L}} \frac{d \tau_{L}}{d \tau_{X}}+\frac{\partial l}{\partial \pi} \frac{d \pi}{d \tau_{X}}+\frac{\partial l}{\partial Q} \frac{d Q}{d \tau_{X}}$ along with equations (19), (20) and (21) into (17) and collecting terms gives an expression for the welfare effect of the tax on good $X$ :

$$
\frac{1}{\lambda} \frac{d U}{d \tau_{X}}=\underbrace{\left(\tau_{X}-\tau_{P}\right) \frac{d X}{d \tau_{X}}}_{d W^{P}}+\underbrace{Z\left(X+\tau_{X} \frac{d X}{d \tau_{X}}\right)}_{d W^{R}}-\underbrace{(1+Z) \tau_{L} \frac{\partial l}{\partial p_{X}}}_{d W^{I}}
$$$$
\underbrace{-(1+Z) \tau_{L}\left[\frac{\partial l}{\partial p_{X}}\left(\frac{d p_{X}}{d \tau_{X}}-1\right)+\frac{\partial l}{\partial p_{Y}} \frac{d p_{Y}}{d \tau_{X}}+\frac{\partial l}{\partial \pi} \frac{d \pi}{d \tau_{X}}+\frac{\partial l}{\partial Q} \frac{d Q}{d \tau_{X}}\right]+Z \tau_{L}\left(\frac{d \pi}{d \tau_{X}}-\frac{\partial S}{\partial Q} \frac{d Q}{d \tau_{X}}\right)}_{d W^{I B}}
$$

This expression decomposes the welfare effect into the three components described in the prior literature: the primary welfare effect, $\left(d W^{P}\right)$, the revenue-recycling effect, $\left(d W^{R}\right)$ and the (cost-side) tax-interaction effect $\left(d W^{I}\right)$, plus an additional term, the benefit-side taxinteraction effect $\left(d W^{I B}\right)$. The primary welfare effect is the effect of the tax on the pollution externality, equal to the wedge between the social cost of emissions (the Pigouvian tax) and the private cost (the tax on good $X$ ). The revenue-recycling effect is the efficiency gain from using pollution tax revenue to reduce the labor tax rate, which equals $Z$ times the marginal pollution tax revenue.

Finally, the two tax-interaction effects result when the pollution tax alters households' labor supply decisions, exacerbating or ameliorating the income tax distortion in the labor market. For the cost-side tax-interaction effect $d W^{I}$ (which has been examined in previous studies on this topic) the pollution tax drives up the costs of producing consumer goods, lowering the real wage and discouraging labor supply.

The benefit-side tax-interaction effect $d W^{I B}$ expresses the impact of improved environmental quality on labor supply decisions, through increased labor productivity or improved consumer health. This term did not appear in previous studies, which assumed that environmental quality entered only as a separable term in the utility function. This assumption implied that environmental quality did not influence labor supply, and thus did not create a tax interaction effect. 
The effect $d W^{I B}$ will vary substantially depending on what form the benefits of a better environment take. If environmental quality affects production, then an improved environment can result in lower prices for the affected consumption goods, raising the real wage and encouraging labor supply. If environmental quality reduces time spent sick, households will have more time available for work. On the other hand, if an improved environment reduces medical expenses, households will have more disposable income and therefore less need to work.

Each of the two tax-interaction effects is equal to the distortionary wedge in the labor market (the income tax) times the change in labor supply resulting from the policy. Added to this is the value of any gain or loss in labor tax revenue from the change in labor supply, which equals the change in tax revenue times $Z$. Summing those elements for the change in labor supply from the pollution tax gives the third term in (22), and a similar sum for the change in labor supply from improved environmental quality gives the fourth term.

As has been repeatedly shown in the prior literature (see, for example, Parry (1995)), if the polluting good is a relative complement to leisure (more complementary than the average consumption good), then the cost of environmental regulation will be lower than if it is a relative substitute for leisure. For simplicity, we consider the neutral assumption that goods $\mathrm{X}$ and $\mathrm{Y}$ are equal net substitutes for leisure. ${ }^{6}$ Given this assumption, the cost-side taxinteraction effect can be expressed (see appendix for derivation) as

$$
d W^{I}=Z X
$$

and the benefit-side tax-interaction effect can be written (see appendix) as

$$
d W^{I B}=-Z^{\prime}\left(1-\tau_{L}\right) \frac{d \pi}{d \tau_{X}}-Z\left[\left(p_{X}-\tau_{X}\right) \frac{\partial F_{X}}{\partial Q}+p_{Y} \frac{\partial F_{Y}}{\partial Q}+\left(\frac{Z}{Z}-1\right)\left(\frac{\partial S}{\partial Q}+\frac{\partial M}{\partial Q}\right)-\frac{Z}{Z} \tau_{L} \frac{\partial S}{\partial Q}\right] \frac{d X}{d \tau_{X}}
$$

Together, these imply that the total effect of a pollution tax follows (substituting (23) and (24) into (22))

\footnotetext{
${ }^{6}$ Some other papers on second-best environmental taxes (e.g., Bovenberg and van der Ploeg (1994) and Bovenberg and de Mooij (1994)) make the assumptions that utility is homothetic and that it is weakly separable between leisure and consumption. Together, those assumptions are sufficient to imply that all goods are equal net substitutes for leisure.
} 


$$
\begin{aligned}
& \frac{1}{\lambda} \frac{d U}{d \tau_{X}}=(1+Z) \tau_{X} \frac{d X}{d \tau_{X}}-\tau_{P} \frac{d X}{d \tau_{X}}-Z^{\prime}\left(1-\tau_{L}\right) \frac{d \pi}{d \tau_{X}} \\
& -Z\left[\left(p_{X}-\tau_{X}\right) \frac{\partial F_{X}}{\partial Q}+p_{Y} \frac{\partial F_{Y}}{\partial Q}+\left(\frac{Z}{Z}-1\right)\left(\frac{\partial S}{\partial Q}+\frac{\partial M}{\partial Q}\right)-\frac{Z}{Z} \tau_{L} \frac{\partial S}{\partial Q}\right] \frac{d X}{d \tau_{X}}
\end{aligned}
$$

This indicates that the cost of a pollution tax (the first term) is equal to $1+Z$ times the primary cost of the policy, a familiar result from the prior literature. The total benefit equals the primary benefit of the policy (the second term) plus the benefit-side tax-interaction effect (the remaining terms).

The following sections examine the implications of each of the different effects of environmental quality for the benefit-side tax-interaction effect, and therefore for the optimal pollution tax and the potential benefits of pollution regulation.

\section{B. Labor-Supply-Neutral Externality}

This section assumes that environmental quality appears as a separable term in the utility function, that it has no effect on either health or production, and that production exhibits constant returns to scale. Thus, in this case, $\frac{\partial F_{X}}{\partial Q}, \frac{\partial F_{Y}}{\partial Q}, \frac{\partial S}{\partial Q}, \frac{\partial M}{\partial Q}$ and $\pi$ all equal zero. The prior literature has assumed benefits of this form because in this case changes in environmental quality have no effect on labor supply, and therefore there is no benefit-side tax-interaction effect. This can be seen by examining the third term in (25), which equals zero in this case.

Thus, the expression for the welfare effect of the pollution tax simplifies to

$$
\frac{1}{\lambda} \frac{d U}{d \tau_{X}}=\left(\tau_{X}-\tau_{P}\right) \frac{d X}{d \tau_{X}}+Z \tau_{X} \frac{d X}{d \tau_{X}}
$$

Here, the costs of regulation are magnified by interaction with the tax system, but there is no benefit-side interaction. Solving for the optimum pollution tax gives

$$
\tau_{X}^{*}=\frac{\tau_{P}}{1+Z}
$$

which is substantially less than the Pigouvian tax. 


\section{Externality Affecting Production}

This section assumes that environmental quality affects production of one or both consumption goods, but has no direct effect on individuals' utility or health. Thus, $\frac{\partial U}{\partial Q}, \frac{\partial S}{\partial Q}$, and $\frac{\partial M}{\partial Q}$ all equal zero. In this case, the benefits of pollution regulation will also interact with the labor-market distortion, creating a benefit-side tax interaction in addition to the cost-side tax interaction demonstrated by the prior literature. Using the assumption that there are no utility or health effects gives a simplified expression for the effect of the pollution tax in this case:

$$
\frac{1}{\lambda} \frac{d U}{d \tau_{X}}=(1+Z)\left(\tau_{X}-\tau_{P}\right) \frac{d X}{d \tau_{X}}-Z^{\prime}\left(1-\tau_{L}\right) \frac{d \pi}{d \tau_{X}}
$$

In this case, improved environmental quality lowers the marginal production cost (and therefore the price) for one or both consumption goods, increasing the real wage and encouraging labor supply. Thus, the benefit-side tax-interaction effect produces an additional gain, magnifying the benefits of the pollution tax to the same extent that the costs are magnified. In this case, solving for the optimal pollution tax gives

$$
\tau_{X}^{*}=\tau_{P}+\frac{Z^{\prime}\left(1-\tau_{L}\right) \frac{d \pi}{d \tau_{X}}}{(1+Z) \frac{d X}{d \tau_{X}}}
$$

When environmental quality has no effect on profits (rents) this expression reduces to the Pigouvian tax level. Thus, as long as changes in environmental quality have no effect on profits, the formula for the optimal pollution tax is unchanged by interactions with the distorted labor market. ${ }^{7}$ In this case, both the costs and benefits of the policy are magnified by the same amount. Hence, the optimal pollution tax is the Pigouvian tax, just as in the firstbest case.

\footnotetext{
${ }^{7}$ While the formula for the optimal pollution tax in this case is the same with or without distortionary taxation, equal to the marginal damage from pollution, the actual value for the optimal tax rate will generally be different, because the value of marginal damages will generally change when distortionary taxation is introduced.
} 
Bovenberg and van der Ploeg (1994) achieve a similar result through a somewhat different model. The results from this section generalize and extend their analysis in three main respects. First, their analysis assumed that environmental quality affects all industries equally. The model presented here allows environmental quality to have a different effect on productivity in each industry, and demonstrates that the optimal pollution tax is the same as in the first-best case even if the effect of pollution differs across industries.

Second, this model calculates not only the optimal pollution tax, but also the welfare gain from implementing the optimal tax, showing that when environmental quality affects production, the optimal tax is the same, but the potential gain from pollution regulation is substantially greater than in the first-best case. Interaction with the tax system magnifies both the benefits and the costs of pollution regulation to the same degree; each is equal to the MCPF times its first-best level. The welfare gain from any given pollution tax, being equal to the benefits minus the costs, is magnified to the same extent as benefits and costs. Thus, the potential gain from pollution regulation in the second-best is equal to the MCPF times the potential gain in a first-best setting.

Third, this model allows for rents from production of one or both goods, and demonstrates that the optimal pollution tax is the same as in the first-best case only if environmental quality has no effect on producer rents. As can be seen from examining equation (30), if increased environmental quality does increase rents, then the optimal pollution tax will be lower than the Pigouvian level (note that the denominator of the second term is negative). ${ }^{8}$ Unlike increased labor productivity, increased profits represent a benefit with no direct effect on labor supply. As a result, benefits in the form of increased profits are not magnified by tax interactions. Since the costs are still magnified, if any benefits come in the form of increased rents, the optimal pollution tax will be less than the Pigouvian tax. ${ }^{9}$ Global climate change may well have effects of this kind-to the extent that global warming

\footnotetext{
${ }^{8}$ This result is similar to that found by Williams (1999) in the context of optimal tariffs on international trade in a tax-distorted economy.

${ }^{9}$ On the other hand, if improved environmental quality increases labor productivity but reduces rents (by reducing the productivity of a fixed factor such as land), the optimal second-best tax will exceed the Pigouvian tax. It is difficult to conceive of an example of such a case, however.
} 
decreases the productivity of farmland, preventing climate change will preserve landowners' rents.

\section{Externality with Health Effects}

This section considers the case where environmental quality has health effects, but no productivity or utility effects. Thus, in this case, $\frac{\partial U}{\partial Q}, \frac{\partial F_{X}}{\partial Q}$, and $\frac{\partial F_{Y}}{\partial Q}$ equal zero. For simplicity, this section also assumes that production exhibits constant returns to scale, so $\pi=0$. Like productivity effects, health effects will influence labor supply decisions, and the sign of the change in labor supply will depend on the particular form of the health effect. Using the assumption that there are no utility or productivity effects gives a simplified expression for the effect of the pollution tax in this case:

$$
\frac{1}{\lambda} \frac{d U}{d \tau_{X}}=\left[\left(\tau_{X}-\tau_{P}\right)+Z \tau_{X}+Z \tau_{L} \frac{\partial S}{\partial Q}-(Z-Z)\left(\frac{\partial S}{\partial Q}+\frac{\partial M}{\partial Q}\right)\right] \frac{d X}{d \tau_{X}}
$$

Examining this expression shows that if an improved environment results in lower expenses for medical care, the benefit-side tax-interaction effect will reduce the benefit of regulation, whereas if an improved environment allows individuals to lose less time to illness, then the sign of the benefit-side tax-interaction effect is ambiguous and depends on the tax rate and labor elasticities.

This result appears because both types of health damage cause an income effect. Reducing either medical expenses or time lost to illness increases household disposable income, causing increased consumption of leisure and exacerbating the labor market distortion. An offsetting effect occurs when an improved environment reduces time lost to illness because households have more time available for labor, thus generating a gain from additional labor tax revenues.

Solving for the optimal pollution tax yields

$$
\tau_{X}^{*}=\frac{1}{1+Z}\left[\tau_{P}-Z \tau_{L} \frac{\partial S}{\partial Q}+(Z-Z)\left(\frac{\partial S}{\partial Q}+\frac{\partial M}{\partial Q}\right)\right]
$$

which is less than the Pigouvian tax level. It may be more or less than the optimum tax in the earlier case where environmental quality had a separable effect on utility-depending on 
whether the sum of the second and third terms in the numerator is positive or negative-but will likely be lower. If improved environmental quality results in decreased medical expenses, then the optimal tax will be lower, whereas if it results in decreased time spent sick, the optimal tax may be higher or lower.

Combining both effects, if $-\tau_{L} \frac{\partial S}{\partial Q}<-\left(1-\frac{Z}{Z^{\prime}}\right)\left(\frac{\partial S}{\partial Q}+\frac{\partial M}{\partial Q}\right)$ then the optimal tax will be lower than in the case when environmental quality had no effect on labor supply. Assuming that the labor tax rate is 0.4 , the MCPF is 1.11 (implying that $Z=0.11$ ), and the MEB is $0.3^{10}$ suggests that the optimal tax will be lower than when environmental quality doesn't affect labor supply if either type of health effect is present. Only if the MCPF is large relative to the MEB (which will occur when the uncompensated labor supply elasticity is large compared to the income elasticity of labor supply), and if the fraction of benefits that appear as reduced medical costs are small relative to the gain from reduced time lost to sickness, will the optimal tax be greater than when pollution doesn't affect labor supply.

Table 1 summarizes the results from the last three sections, showing the marginal benefits of regulation and the optimal level of the pollution tax for the different channels through which pollution can affect welfare. It shows that the benefit-side tax-interaction effect magnifies benefits that take the form of improved labor productivity (thus increasing the optimal level of regulation) but diminishes benefits that take the form of improved health (thus reducing the optimal level of regulation). These effects on the benefits of regulation are of roughly the same magnitude as the effects on the costs of regulation addressed by the prior literature.

\section{E. Extending the Model to Allow Consumer Choice in Health Care}

Thus far, we have assumed that consumers have no choice in their consumption of medical care, which is determined only by the level of environmental quality. This section

\footnotetext{
${ }^{10}$ An uncompensated labor supply elasticity of 0.15 and an income elasticity of labor supply of -0.25 , together with a labor tax rate of 0.4 imply these values for the MCPF and MEB. These elasticities are roughly consistent with those found by Fuchs, Krueger, and Poterba (1998) in a survey of labor economists. A labor tax rate of 0.4 is a standard assumption in the literature, as in Browning (1987).
} 
expands the previous model, allowing consumers to choose their medical spending, and adding consumer health as an argument in the utility function. In this extended model, the sign of the benefit-side tax-interaction effect is somewhat smaller, but its sign stays the same.

For simplicity, this section will assume that the only effect of environmental quality is on individual health. Therefore, environmental quality will not appear directly in the utility or production functions. In the extended model presented in this section, utility directly depends on health. Thus, equation (1) becomes ${ }^{11}$

$$
U(V(l, X, Y), H)
$$

where $H$ is consumer health, which is assumed to be weakly separable from leisure and consumption. ${ }^{12}$ Health is determined by the level of environmental quality and by individual spending on medical care. Thus

$$
H=H(M, Q)
$$

which is continuous, quasi-concave, and increasing in both $M$ and $Q . M$ is now chosen by the consumer, rather than being a function of environmental quality as in the earlier model. For simplicity, all production is assumed to exhibit constant returns to scale, which implies that there are no rents.

In this extended model, the cost-side tax-interaction effect is unchanged. The benefit-side tax-interaction effect can now be expressed (see appendix for derivation) as

$$
d W^{I B}=\left(Z^{\prime}-Z\right)\left(1-\frac{\partial M}{\partial I}\right)^{-1} \frac{\partial M}{\partial Q} \frac{d Q}{d \tau_{X}}
$$

Making the same assumption as before, that both consumption goods are equal substitutes for leisure, implies that the total effect of a pollution tax can be approximated as

\footnotetext{
${ }^{11}$ Throughout this section, each equation that replaces a corresponding equation from the earlier model will denoted by the number of the equation it replaces and a prime ('). Thus, equation (1') replaces equation (1) in this extended model.

${ }^{12}$ For the same reasons as in the case where environmental quality appears in the utility function, the benefit-side tax-interaction effect would differ if health appeared as a non-separable term. There is no obvious reason why one would expect good health to favor consumption over leisure or vice-versa. Thus, the separability assumption here represents a reasonable central case. Furthermore, if health were not weakly separable in utility, then it would be optimal for the government to tax (if health is a leisure complement) or subsidize (if health is a leisure substitute) medical care.
} 


$$
\frac{1}{\lambda} \frac{d U}{d \tau_{X}}=(1+Z) \tau_{X} \frac{d X}{d \tau_{X}}-\tau_{P} \frac{d X}{d \tau_{X}}-(Z-Z)\left(1-\frac{\partial M}{\partial I}\right)^{-1} \frac{\partial M}{\partial Q} \frac{d X}{d \tau_{X}}
$$

As in the previous model, where individuals had no choice in their consumption of medical care, the benefit-side tax-interaction effect reduces the benefit of a cleaner environment. When individuals can choose how much medical care they consume, the effects of a cleaner environment will appear in two ways: improved health and reduced medical expenses. The effect on leisure demand and the consequent benefit-side tax-interaction effect will simply combine the effects of improved health and reduced medical expenses on leisure demand.

So long as health enters as a weakly separable term in the utility function, improved health will not affect the labor/leisure choice and therefore will not create a benefit-side taxinteraction effect. Reduced medical spending, however, does affect leisure demand. As in the previous model, reduced medical spending raises household disposable income, resulting in increased demand for leisure. Thus, to the extent that improved environmental quality results in reduced medical spending ${ }^{13}$, the benefit-side tax-interaction effect will be negative, and therefore the benefits of a given environmental tax will be lower.

The magnitude of the benefit-side tax-interaction effect in this case is smaller than in the earlier case where consumers had no choice in their consumption of health care, because in this case consumers take part of the benefit of improved environmental quality in the form of improved health. Thus, a given environmental improvement produces a smaller reduction in health care expenditure and consequently a smaller benefit-side tax-interaction effect. Still, the concept behind the benefit-side tax-interaction, and the sign of the effect remain the same.

Solving for the optimal pollution tax in this extended model yields

$$
\tau_{X}^{*}=\frac{1}{1+Z}\left[\tau_{P}+\left(Z^{\prime}-Z\right)\left(1+\frac{\partial M}{\partial I}\right)^{-1} \frac{\partial M}{\partial Q}\right]
$$

\footnotetext{
${ }^{13}$ Note that the benefit-side tax-interaction effect could be positive in this case if the effect of improved environmental quality were to increase health care expenditure. This seems unlikely, and thus such a case is not considered here.
} 
As would be expected, the negative benefit-side tax-interaction effect again leads to an optimal pollution tax that is below the optimal tax if environmental quality were to appear as a separable term in the utility function, and is well below the Pigouvian level.

\section{Conclusions}

Prior research has shown that interactions with a tax-distorted labor market can significantly magnify the costs of pollution regulation, and that the extent to which those costs are magnified will depend on the regulatory instrument used. This paper demonstrates that a similar principle holds on the benefit side. The benefit-side tax interaction effect can magnify or diminish the benefits of reduced pollution, with the effect depending on just what form such benefits take. This effect is potentially very important; it can alter the benefits of environmental regulation to as great an extent as the second-best effects noted by the prior literature change the costs of regulation.

When the benefits of regulation do not affect labor supply-the case typically considered in the prior literature-such benefits are neither magnified nor diminished by interactions with a distorted labor market. Since these interactions do magnify the costs of regulation, the potential benefit from regulation is lower than in the first-best case, as is the optimal level of regulation.

In contrast, when the benefit from reduced pollution is to increase production efficiency in one or more industries, the benefit-side tax interaction can substantially magnify the benefits of pollution regulation. This gain depends on what proportion of the increased efficiency appears as increased labor productivity, and what proportion appears as increased profits (rents to an implicit fixed factor). If the entire benefit comes in the form of increased labor productivity, then the benefits are magnified to the same extent as the costs of regulation. Thus, the optimal pollution tax is the same as in the first-best case, and the potential net welfare gain from regulation is substantially increased.

If, on the other hand, the entire benefit comes in the form of increased rents, then there is no benefit-side tax interaction, just as in the case in which environmental quality does not affect labor supply. Thus, the optimal pollution tax and the net gain from imposing that 
tax will be lower than they would be in the first-best case. A large portion of the benefits of preventing global climate change might fall into this category, preserving the value of agricultural land, but having little effect on labor productivity.

When pollution affects health, the sign of the benefit-side interaction depends on whether the gain from reduced pollution appears as reduced medical costs, fewer lost work days, or some combination of the two. Interactions with the distorted labor market diminish the benefit of reducing medical costs, but have an ambiguous effect on the benefit of reducing time lost to illness. Estimates of labor elasticities suggest that the optimal pollution tax in a case with both health effects will be lower than when the environmental quality doesn't affect labor supply, and will be dramatically lower than in the first-best case, because in this case interactions with the tax system magnify the policy's costs while diminishing its benefits.

While this model focuses only on the case of environmental regulation, the insight it provides is more general. The benefit-side tax-interaction effect depends not on the particular type of regulation, but on the labor-supply effects of improved health or productivity. Thus, this effect should apply equally to a broad range of other policies that affect health or productivity, such as occupational health and safety rules or subsidies for research and development.

Calculating the magnitude of these benefit-side tax interactions for the regulation of a particular pollutant should not be too difficult. The necessary parameter values-the proportion of damages coming from each of the several possible channels-are typically produced as intermediate steps in empirical studies that value pollution damages.

These benefit-side interactions can have just as great an effect as the cost-side interactions considered by prior work. Future studies, both of environmental regulation and of other regulations affecting health and productivity, should consider the benefit-side tax interactions as well as the cost-side tax interactions in estimating the optimal level of regulation and the potential gains from such regulation. Studies that fail to consider these second-best effects could prove to be substantially misleading. 


\section{References}

Bovenberg, A. Lans, and Ruud A. de Mooij, 1994. "Environmental Levies and Distortionary Taxation." American Economic Review 84(4):1085-9.

Bovenberg, A. Lans and Lawrence H. Goulder, 1996. "Optimal Environmental Taxation in the Presence of Other Taxes: General Equilibrium Analyses." American Economic Review 86:985-1000

Bovenberg, A. Lans and Lawrence H. Goulder, 1997. "Costs of Environmentally-Motivated Taxes in the Presence of other Taxes: General Equilibrium Analyses." National Tax Journal L:59-87

Bovenberg, A. Lans and F. van der Ploeg, 1994 "Green Policies and Public Finance in a Small Open Economy." Scandinavian Journal of Economics 96:343-63

Browning, Edgar K., 1987. "On the Marginal Welfare Cost of Taxation.” American Economic Review 77:11-23.

Environmental Protection Agency, 1997. "The Benefits and Costs of the Clean Air Act 1970 to $1990 "$

Environmental Protection Agency, 1999. "The Benefits and Costs of the Clean Air Act 1990 to $2010 "$

Fuchs, Victor R., Alan B. Krueger and James M. Poterba, 1998. "Economists' Views about Parameters, Values and Policies: Survey Results in Labor and Public Economics." Journal of Economic Literature 36(3): 1387-1425.

Fullerton, Don and Gilbert Metcalf, 2000. "Environmental Controls, Scarcity Rents, and PreExisting Distortions." Journal of Public Economics, forthcoming

Goulder, Lawrence H., 1995. "Environmental Taxation and the 'Double Dividend': A Reader's Guide." International Tax and Public Finance 2(2):157-183.

Goulder, Lawrence H., Ian W. H. Parry, and Dallas Burtraw, 1997. "Revenue-Raising vs. Other Approaches to Environmental Protection: The Critical Significance of Pre-Existing Tax Distortions." Rand Journal of Economics 28:708-731

Goulder, Lawrence H., Ian W. H. Parry, Roberton C. Williams III, and Dallas Burtraw, 1999. "The Cost-Effectiveness of Alternative Instruments for Environmental Protection in a Second-Best Setting," Journal of Public Economics, 72:329-360.

Parry, Ian W. H., 1995. "Pollution Taxes and Revenue Recycling." Journal of Environmental Economics and Management 29:S64-S77

Parry, Ian W. H., Roberton C. Williams III, and Lawrence H. Goulder, 1999. "When Can Carbon Abatement Policies Increase Welfare? The Fundamental Role of Distorted Factor Markets." Journal of Environmental Economics and Management, 37:52-84

Williams, Roberton C., III, 1999. "Revisiting the Cost of Protectionism: The Role of Tax Distortions in the Labor Market." Journal of International Economics, 47:459-77 
Table 1

Significance of Alternative Benefit Channels for the Effects of Regulation

(all values expressed as a percentage of the first-best level)

\begin{tabular}{|c|c|c|}
\hline Effect of Pollution & $\begin{array}{c}\text { Marginal Benefits } \\
\text { of Regulation } \\
\text { (at any given level } \\
\text { of regulation) }\end{array}$ & $\begin{array}{c}\text { Optimal } \\
\text { Pollution Tax }\end{array}$ \\
\hline $\begin{array}{c}\text { Labor-Supply Neutral } \\
\text { (case considered by } \\
\text { prior literature) }\end{array}$ & $100 \%$ & $90 \%$ \\
\hline $\begin{array}{c}\text { Reduced Labor } \\
\text { Productivity }\end{array}$ & $111 \%$ & $100 \%$ \\
\hline $\begin{array}{c}\text { Reduced Fixed-Factor } \\
\text { Productivity }\end{array}$ & $93 \%$ & $84 \%$ \\
\hline Increased Medical \\
Expenses
\end{tabular}

Assumptions:

$Z$ (marginal cost of public funds minus one $)=0.11$

$Z($ marginal excess burden $)=0.3$

$\tau_{L}($ pre-existing labor tax rate $)=0.4$

Note: These parameter assumptions imply that the marginal cost of regulation in all cases is $111 \%$ of the marginal cost in the first-best case. 


\section{Appendix}

\section{Derivation of Equation (23)}

The expression for the (cost-side) tax-interaction effect from equation (22) is:

(A1) $\quad d W^{I}=(1+Z) \tau_{L} \frac{\partial l}{\partial p_{X}}$

Substituting in the definition of the MCPF (20) yields

(A2) $d W^{I}=Z(L+\pi+G) \frac{\frac{\partial l}{\partial p_{X}}}{\frac{\partial l}{\partial \tau_{L}}}$

The Slutsky equation gives

$$
\frac{\partial l}{\partial p_{X}}=\frac{\partial l^{C}}{\partial p_{X}}-\frac{\partial l}{\partial I} X
$$

and

(A4) $\frac{\partial l}{\partial \tau_{L}}=\frac{\partial l^{C}}{\partial \tau_{L}}-\frac{\partial l}{\partial I}(T-l+\pi)$

where $I$ is after-tax non-labor income.

Taking a total differential of the household utility function (1), holding the levels of utility and of environmental quality constant and substituting in the consumer first-order conditions (11) yield

(A5) $\frac{\partial l^{C}}{\partial \tau_{L}}=-\frac{\partial l^{C}}{\partial\left(1-\tau_{L}\right)}=\frac{p_{X}}{1-\tau_{L}} \frac{\partial X^{C}}{\partial\left(1-\tau_{L}\right)}+\frac{p_{Y}}{1-\tau_{L}} \frac{\partial Y^{C}}{\partial\left(1-\tau_{L}\right)}$

The Slutsky symmetry property gives

(A6) $\frac{\partial l^{C}}{\partial P_{X}}=\frac{\partial X^{C}}{\partial\left(1-\tau_{L}\right)}$ and

(A7) $\frac{\partial l^{C}}{\partial P_{Y}}=\frac{\partial Y^{C}}{\partial\left(1-\tau_{L}\right)}$

and the assumption that $X$ and $Y$ are equal substitutes for leisure implies that

(A8) $\frac{\partial X^{C}}{\partial\left(1-\tau_{L}\right)} \frac{\left(1-\tau_{L}\right)}{X}=\frac{\partial Y^{C}}{\partial\left(1-\tau_{L}\right)} \frac{\left(1-\tau_{L}\right)}{Y}$

Substituting equations (A4) through (A8) into (A3) and collecting terms yields 
(A9) $\frac{\partial l}{\partial p_{X}}=\frac{\partial l}{\partial \tau_{L}} \frac{X}{L+\pi+G}$

Substituting (A9) into (A2) yields (23).

Derivation of Equation (24)

The expression for the benefit-side tax-interaction effect from equation (22) is:

$$
d W^{I B}=-(1+Z) \tau_{L}\left[\frac{\partial l}{\partial p_{X}}\left(\frac{d p_{X}}{d \tau_{X}}-1\right)+\frac{\partial l}{\partial p_{Y}} \frac{d p_{Y}}{d \tau_{X}}+\frac{\partial l}{\partial \pi} \frac{d \pi}{d \tau_{X}}+\frac{\partial l}{\partial Q} \frac{d Q}{d \tau_{X}}\right]+Z \tau_{L}\left(\frac{d \pi}{d \tau_{X}}-\frac{\partial S}{\partial Q} \frac{d Q}{d \tau_{X}}\right)
$$

The same steps used to derive (A9) can be repeated for good $Y$ to yield

(A11) $\frac{\partial l}{\partial p_{Y}}=\frac{\partial l}{\partial \tau_{L}} \frac{Y}{L+\pi+G}$

Taking a total derivative of the production function for good $X(3)$, substituting in the equation for the price of $X(6)$ and rearranging yield

(A12) $\left(p_{X}-\tau_{X}\right) d X=d L_{X}+\left(p_{X}-\tau_{X}\right) \frac{\partial F_{X}}{\partial Q} d Q$

and the same approach for good $Y$ gives

(A13) $p_{Y} d Y=d L_{Y}+p_{Y} \frac{\partial F_{Y}}{\partial Q} d Q$

Taking a total derivative of profits (8) and substituting in (A12) and (A13) give

(A14) $d \pi=X\left(d p_{X}-d \tau_{X}\right)+Y d p_{Y}+\left[\left(p_{X}-\tau_{X}\right) \frac{\partial F_{X}}{\partial Q}+p_{Y} \frac{\partial F_{Y}}{\partial Q}\right] d Q$

Because the productivity effects of $Q$ on $l$ are already accounted for by the $p_{X}, p_{Y}$ and $\pi$ terms, the partial derivative $\frac{\partial l}{\partial Q}$ represents only the health effects. These affect demand by reducing the income available for leisure and the two consumption goods. Thus,

(A15) $\frac{\partial l}{\partial Q}=-\frac{\partial l}{\partial I}\left[\left(1-\tau_{L}\right) \frac{\partial S}{\partial Q}+\frac{\partial M}{\partial Q}\right]$

$I$ represents after-tax income, while $\pi$ is pre-tax profits, so

(A16) $\frac{\partial l}{\partial \pi}=\left(1-\tau_{L}\right) \frac{\partial l}{\partial I}$

Substituting (A9), (A11), (A14), (A15) and (A16) into (A10) and collecting terms yields 
(A17) $d W^{I B}=-Z\left(1-\tau_{L}\right) \frac{d \pi}{d \tau_{X}}+\left[\left(p_{X}-\tau_{X}\right) \frac{\partial F_{X}}{\partial Q}+p_{Y} \frac{\partial F_{Y}}{\partial Q}\right] \frac{d Q}{d \tau_{X}}-Z \tau_{L} \frac{\partial S}{\partial Q} \frac{d Q}{d \tau_{X}}$

$$
+(1+Z) \tau_{L} \frac{\partial l}{\partial I}\left\{\left[\left(1-\tau_{L}\right) \frac{\partial S}{\partial Q}+\frac{\partial M}{\partial Q}\right] \frac{d Q}{d \tau_{X}}-\left(1-\tau_{L}\right) \frac{d \pi}{d \tau_{X}}\right\}
$$

Substituting the definitions of the MCPF and MEB (20) and (21) into (A4) and rearranging yield

$$
Z-Z=(1+Z) \tau_{L} \frac{\partial l}{\partial I}
$$

Substituting (A18) into (A17) and rearranging yield equation (24).

\section{Derivation of Equation (24')}

Following a similar approach to that used in the original model, we can obtain the same result as equation (17) for the effect of the pollution tax, though in this case, the Pigouvian tax level $\tau_{P}$ is given by

$$
\tau_{P}=\frac{1}{\lambda} \frac{\partial U}{\partial H} \frac{\partial H}{\partial Q}
$$

Substituting $\frac{d l}{d \tau_{X}}=\frac{\partial l}{\partial p_{X}} \frac{d p_{X}}{d \tau_{X}}+\frac{\partial l}{\partial p_{Y}} \frac{d p_{Y}}{d \tau_{X}}+\frac{\partial l}{\partial \tau_{L}} \frac{d \tau_{L}}{d \tau_{X}}+\frac{\partial l}{\partial \pi} \frac{d \pi}{d \tau_{X}}+\frac{\partial l}{\partial Q} \frac{d Q}{d \tau_{X}}$ along with equations (19), (20) and (21) into (17), using $d p_{X}=d \tau_{X}, d p_{Y}=0$, and $d \pi=0$ (which are implied by the assumptions that environmental quality does not affect productivity and that production exhibits constant returns to scale) and collecting terms gives an expression for the welfare effect of the tax on good $X$ :

$$
\frac{1}{\lambda} \frac{d U}{d \tau_{X}}=\underbrace{\left(\tau_{X}-\tau_{P}\right) \frac{d X}{d \tau_{X}}}_{d W^{P}}+Z \underbrace{Z\left(X+\tau_{X} \frac{d X}{d \tau_{X}}\right)}_{d W^{R}}-\underbrace{(1+Z) \tau_{L} \frac{\partial l}{\partial p_{X}}}_{d W^{I}} \underbrace{-(1+Z) \tau_{L} \frac{\partial l}{\partial Q} \frac{d Q}{d \tau_{X}}-Z \tau_{L} \frac{\partial S}{\partial Q} \frac{d Q}{d \tau_{X}}}_{d W^{I B}}
$$

which, not surprisingly, is again very similar to the same expression from the original model, though the benefit-side tax-interaction effect term is greatly simplified by the assumption that environmental quality does not affect productivity. The expression for the benefit-side taxinteraction effect from equation (A20) can be rewritten as: 
(A21) $d W^{I B}=-Z(L+\pi+G) \frac{\frac{\partial l}{\partial Q}}{\frac{\partial l}{\partial \tau_{L}}} \frac{d Q}{d \tau_{X}}$

The change in spending on $X, Y$, and $l$ for a change in $I$ will equal

(A22) $\left(1-\tau_{L}\right) \frac{\partial l}{\partial I}+\left(1+\tau_{X}\right) \frac{\partial X}{\partial I}+\frac{\partial Y}{\partial I}=1-\frac{\partial M}{\partial I}$

For a change in $Q$ that change will be

(A23) $\left(1-\tau_{L}\right) \frac{\partial l}{\partial Q}+\left(1+\tau_{X}\right) \frac{\partial X}{\partial Q}+\frac{\partial Y}{\partial Q}=-\frac{\partial M}{\partial Q}$

Weak separability of health in the utility function implies that leisure demand is determined solely by the relative prices of $l, X$, and $Y$ (which are not affected by changes in $Q$ ) and by the amount spent on those goods. Together with (A22) and (A23), this implies

(A24) $\frac{\partial l}{\partial Q}=-\frac{\partial l}{\partial I}\left(1-\frac{\partial M}{\partial I}\right)^{-1} \frac{\partial M}{\partial Q}$

Substituting (A24) into (A21) and rearranging using (A18) yields equation (24') 